\title{
The Association between Modulating Inflammatory Cytokines and Constipation of Geriatrics in Iran
}

\author{
Marjan Mokhtare ${ }^{1}$, Rahele Alimoradzadeh ${ }^{2}$, Shahram Agah ${ }^{3, *}$, \\ Hossein Mirmiranpour ${ }^{4}$, Niloofar Khodabandehloo ${ }^{5}$
}

1. Assistant professor of Gastroenterology ,Colorectal Research Center, Iran University of Medical Sciences, Tehran, Iran

2. Rezident, Internal Medicine Department, Iran University of Medical Sciences, Tehran, Iran

3. Professor of Gastroenterology, Colorectal Research Center, Iran University of Medical Sciences, Tehran, Iran

4. Assistant Professor, Department of Biochemistry, Colorectal Research Center, Iran University of Medical Sciences, Tehran, Iran

5. Assistant Professor, Internist, Internal Medicine Department, Colorectal Research Center, Iran University of Medical Sciences, Tehran, Iran

\section{* Corresponding Author:}

Shahram Agah, MD

Colorectal Research Center, Iran University of Medical Sciences, Tehran, Iran Telefax: + 982166554790

Email: shahramagah@gmail.com

Received: 20 Jul. 2017

Accepted: 18 Sep. 2017

\section{ABSTRACT}

\section{BACKGROUND}

The effect of changes in intestinal microbiota on constipation is contraversial. Constipation is more prevalent in elderly. Therefore, the current study was designed to assess the role of modulating inflammatory cytokines in old age patients with constipation by evaluating the serum levels of tumor necrosis factor alpha (TNF- $\alpha$ ), interleukin 1 (IL-1), and interleukin 6 (IL-6).

\section{METHODS}

This case-control study was done on 100 participants, aged 65 years or higher, with and without functional constipation according to ROME III criteria (50 participants in each group). Baseline demographic, clinical characteristics, and serum levels of TNF- $\alpha$, IL-1, and IL-6 were compared between the case and control groups. Independent $t$ test and Chi-square test were used for analysis of data.

\section{RESULTS}

Mean levels of TNF- $\alpha$, IL-1, and IL-6 were $(666.80 \pm 101.40 \mathrm{pg} / \mathrm{mL}$ vs. $489.20 \pm 53.68 \mathrm{pg} / \mathrm{mL}$, $p<0.001),(435.96 \pm 52.31 \mathrm{pg} / \mathrm{mL}$ vs. $296.44 \pm 45.50 \mathrm{pg} / \mathrm{mL}, p<0.001)$ and $(438.18 \pm 59.57 \mathrm{pg} / \mathrm{mL}$ vs. $290.14 \pm 36.39 \mathrm{pg} / \mathrm{mL}, p<0.001)$ in the case and control groups, respectively. A reverse correlation was found between the aging process and TNF- $\alpha(\mathrm{r}=-0.26 ; p=0.04)$, as well as IL-1 level $(\mathrm{r}=-0.41 ; p=0.003)$ in the control group. A direct correlation was observed between the aging process and TNF- $\alpha(\mathrm{r}=0.40 ; p=0.004)$ and IL- $6(\mathrm{r}=0.44 ; p=0.002)$ levels in the case group.

\section{CONCLUSION}

This study showed a significant association between the serum level of modulating inflammatory cytokines and age-related constipation in Iranian subjects. It seems that the serum level of modulating inflammatory cytokines can be affected by diversity and abundance in the gut microbiota. The role of diversity in microbial population and their abundance in gut must be evaluated in further studies.

\section{KEYWORDS:}

Inflammatory cytokine; Constipation; Geriatrics; Iran

\section{Please cite this paper as:}

Mokhtare M, Alimoradzadeh R, Agah S, Mirmiranpour H, Khodabandehloo N. The Assiciation between Modulating Inflammatory Cytokines and Constipation of Geriatrics in Iran. Middle East J Dig Dis 2017;9:228-234. doi: 10.15171/mejdd.2017.78.

\section{INTRODUCTION}

Constipation is usually occurred in elderly people. Many studies have been conducted suggesting the potential effects of aging on intestinal microbiota. ${ }^{1}$ However, these changes are not necessarily related to the physiological changes of aging, and may be caused by declining general health, malnutrition, and diet modification, as well as consuming some medications including antibiotics and anti-inflammatory drugs..$^{2-4}$ In fact, the diversity and aboundance of the microbiota can be influenced by the synergistic effects of these physiological and pathological factors. ${ }^{5}$ Moreover, a close association has been revealed between 
colonic transit and intestinal microbiota, so that an increase in transit time can lead to decrease in fecal bacterial capacity. ${ }^{6}$

Various studies have shown a reduction in Bifidobacteria and elevations in Lactobacilli, Streptococci, Enterobacteriaceae, and Clostridia in the intestinal microflora of elderly people. These conversions may lead to changes in colon metabolic environment with important alterations in the concentration and secretory functions of the bowel. ${ }^{7}$ Some studies reported variations in the gut microbiota between healthy individuals and patients with chronic constipation with increased Clostridia. ${ }^{8}$ This dysbiosis may be a factor that promotes constipation. It is proven that alterations in intestinal flora can change intestinal motility and, on the other hand, probiotic bacteria produce short chain fatty acids, which have a key role in transit time. $^{9}$

Physiologically, the intestinal flora is responsible for an appropriate natural defense against the invasion of pathogens as well as preventing the overgrowth of micro-organisms. ${ }^{10}$ Thus any disturbance in the microbiota composition may result in a reduction in the efficacy of the immune system, followed by serious gastrointestinal infections that are more highlighted in the elderly. ${ }^{11}$ Along with this immunological alteration, the response mediated by lymphocytes may be altered and thus the circulatory levels of antibodies and also inflammatory biomarkers such as interleukins may significantly change. These changes may be in parallel and empowered by the changes in mucosal permeability and gastric acid secretion in the elderly. ${ }^{12}$

Besides, it has also been proposed that a close relation exists between the gut microbiota and immune homeostasis and the signals related to intestinal microbiota are critical for immune system development as well as immunoregulation of the secretion of antimicrobial peptides, chemokines, and cytokines. ${ }^{13-15}$ However, there is still controversy regarding the effect of changes in modulating inflammatory cytokines on constipation. Therefore, the current study was designed to assess the role of modulating inflammatory cytokines among elderly patients with constipation by measuring the serum levels of interleukin 1 (IL-1), interleukin 6 (IL-6), and tumor necrosis factor alpha (TNF- $\alpha)$.

\section{MATERIALS AND METHODS}

\section{Study design and setting}

This is a case-control study performed on 100 participants aged 65 years or higher (50 with constipation and 50 without constipation) referred to the gastrointestinal clinic at Rasoul-e-Akram Teaching Hospital in Tehran. This study was approved by the Ethics Committee of Iran University of Medical Sciences with ethic code number:105/5954.

\section{Participants}

Included subjects were old age patients (age $\geq 65$ years) with and without functional constipation based on Rome III criteria. ${ }^{16}$

Exclusion criteria were a history of autoimmune disorders, connective tissue disease, irritable bowel syndrome, inflammatory bowel disease, acute infections, thyroid disorder, diabetes mellitus, cancer, dementia, Parkinson disease, history of consuming antibiotics within the last 3 months, history of receiving immunosuppressive and antidepressant drugs, and calcium chanel blockers. The body mass index (BMI) also ranged from 19 to $30 \mathrm{~kg} / \mathrm{m}^{2}$ in both groups.

\section{Measurements}

Medical history was taken from all the participants and they were clinically evaluated. Written informed consent was obtained from them. And then, $10 \mathrm{cc}$ venous blood samples were taken and sent for laboratory tests. The mental state of the participants was evaluated using Mini-mental State Examination (MMSE). ${ }^{17}$ In this test, 25 cut-off points were used for determining the presence of dementia in all participants. ${ }^{18}$

The primary purpose of this study was to evaluate and compare the serum levels of TNF- $\alpha$, IL-1, and IL- 6 between the case and control groups. The levels of IL-1 and IL- 6 were assessed by immunoenzymometric assay (DIACLONE kit, France) and TNF- $\alpha$ level was assessed using enzyme-linked immunosorbent assay (ELISA) (Sandwich) method (R\&D SYSTEMS kit, USA). All measurements were done using a Mindray ELISA reader instrument (MR-96A model, Germany).

\section{Statistical analysis}

Analysis of data was performed using SPSS software 
Table 1: Baseline demographic and clinical characteristics of the subjects

\begin{tabular}{|c|c|c|c|c|c|}
\hline Variables & & Control $(n=50)$ & Case $(n=50)$ & Total $(n=100)$ & $p$ \\
\hline Age (mean \pm SD; year) & & $77.72 \pm 8.41$ & $77.06 \pm 7.94$ & $77.39 \pm 8.14$ & 0.69 \\
\hline \multirow[t]{2}{*}{$\operatorname{Sex}(n, \%)$} & Male & $28(56.0)$ & $21(42.0)$ & $49(49.0)$ & \multirow{2}{*}{0.16} \\
\hline & Female & $22(44.0)$ & $29(58.0)$ & $51(51.0)$ & \\
\hline \multirow[t]{2}{*}{ Body mass index $\left(\mathrm{n}, \% ; \mathrm{kg} / \mathrm{m}^{2}\right)$} & Normal & $26(52.0)$ & $28(56.0)$ & $54(54.0)$ & \multirow{2}{*}{0.69} \\
\hline & Overweight & $24(48.0)$ & $22(44.0)$ & $46(46.0)$ & \\
\hline \multirow[t]{5}{*}{ MMSE score (n, \%) } & 26 & $23(46.0)$ & $17(34.0)$ & $40(40.0)$ & \multirow{5}{*}{0.37} \\
\hline & 27 & $9(18.0)$ & $11(22.0)$ & $20(20)$ & \\
\hline & 28 & $6(12.0)$ & $7(14.0)$ & $13(13.0)$ & \\
\hline & 29 & $8(16.0)$ & $14(28.0)$ & $22(22.0)$ & \\
\hline & 30 & $4(8.0)$ & $1(2.0)$ & $5(5.0)$ & \\
\hline
\end{tabular}

n: Number of participants; SD: Standard deviation; MMSE: Mini-mental State Examination

Table 2: The mean serum levels of inflammatory modulating cytokines for age subgroups of the participants

\begin{tabular}{|c|c|c|c|c|c|}
\hline Age groups & & Control $(n=50)$ & Case $(n=50)$ & Total $(n=100)$ & $P$-value \\
\hline \multirow[t]{3}{*}{65 to 75 years } & $\mathrm{TNF}-\alpha(\mathrm{pg} / \mathrm{mL})$ & $599.70 \pm 89.68$ & $521.06 \pm 19.78$ & $561.56 \pm 82.40$ & $<0.001$ \\
\hline & IL-1 (pg/mL) & $435.50 \pm 50.32$ & $326.06 \pm 28.13$ & $383.95 \pm 75.07$ & $<0.001$ \\
\hline & IL-6 (pg/mL) & $412.80 \pm 63.55$ & $296.81 \pm 44.35$ & $365.98 \pm 84.57$ & $<0.001$ \\
\hline \multirow[t]{3}{*}{76 to 85 years } & $\mathrm{TNF}-\alpha(\mathrm{pg} / \mathrm{mL})$ & $636.71 \pm 87.93$ & $481.75 \pm 54.75$ & $560.32 \pm 84.67$ & $<0.001$ \\
\hline & IL-1 (pg/mL) & $428.71 \pm 61.82$ & $328.70 \pm 63.05$ & $371.51 \pm 62.78$ & $<0.001$ \\
\hline & IL-6 (pg/mL) & $468.75 \pm 41.75$ & $312.65 \pm 51.25$ & $353.86 \pm 50.13$ & $<0.001$ \\
\hline \multirow[t]{3}{*}{86 to 95 years } & TNF- $\alpha(\mathrm{pg} / \mathrm{mL})$ & $708.44 \pm 111.96$ & $495.64 \pm 51.64$ & $577.33 \pm 108.83$ & $<0.001$ \\
\hline & IL-1 (pg/mL) & $439.69 \pm 54.64$ & $268.86 \pm 48.43$ & $365.37 \pm 53.10$ & $<0.001$ \\
\hline & IL-6 (pg/mL) & $469.25 \pm 53.51$ & $288.14 \pm 40.87$ & $369.25 \pm 52.46$ & $<0.001$ \\
\hline
\end{tabular}

TNF- $\alpha$ : tumor necrosis factor alpha; IL-1: interleukin 1; IL-6: interleukin 6

version 16.0. Quantitative and categorical variables were shown as mean \pm standard deviation (SD) and frequencies and/or percentages, respectively. Normal distribution of data was determined using KolmogorovSmirnov test. Comparison of categorical variables was performed using Chi-square test or Fisher's exact test. Quantitative variables were also compared using t test or Mann-Whitney U test. $p$ values $\leq 0.05$ were considered as statistically significant.

\section{RESULTS}

Demographic and clinical data were recorded for the 100 patients (50 in the case group and 50 in the control group). Both groups were similar regarding age, sex, BMI, and mental status distribution (table 1).

The mean level of TNF- $\alpha$ was significantly higher in the case group $(666.80 \pm 101.40 \mathrm{pg} / \mathrm{mL}$ vs. 489.20 $\pm 53.68 \mathrm{pg} / \mathrm{mL}, p<0.001)$. Similarly, IL-1 levels in the constipation group was considerably higher than the control group (435.96 $\pm 52.31 \mathrm{pg} / \mathrm{mL}$ vs. $296.44 \pm 45.50$ $\mathrm{pg} / \mathrm{mL}, p<0.001)$. Additionally, the group suffering from constipation had higher IL-6 levels in comparison with the control group $(438.18 \pm 59.57 \mathrm{pg} / \mathrm{mL}$ vs. 290.14 $\pm 36.39 \mathrm{pg} / \mathrm{mL}, p<0.001$, table 2).

As shown in table 2, the differences in the three measured cytokines between the case and control groups remained significant in different age subgroups. In this regard, the mean levels of TNF- $\alpha$, IL- 6 , and IL-1 were all higher in participants who experienced constipation compared with those without this complaint in age categories of 65 - 75 years, 75 - 85 years, and 85 - 95 years $(p<0.001)$.

The relationship between aging process and cytokine level patterns were different in the case and control groups. As shown in figure 1, in the control group, there was an adverse correlation between age 


\section{Control}
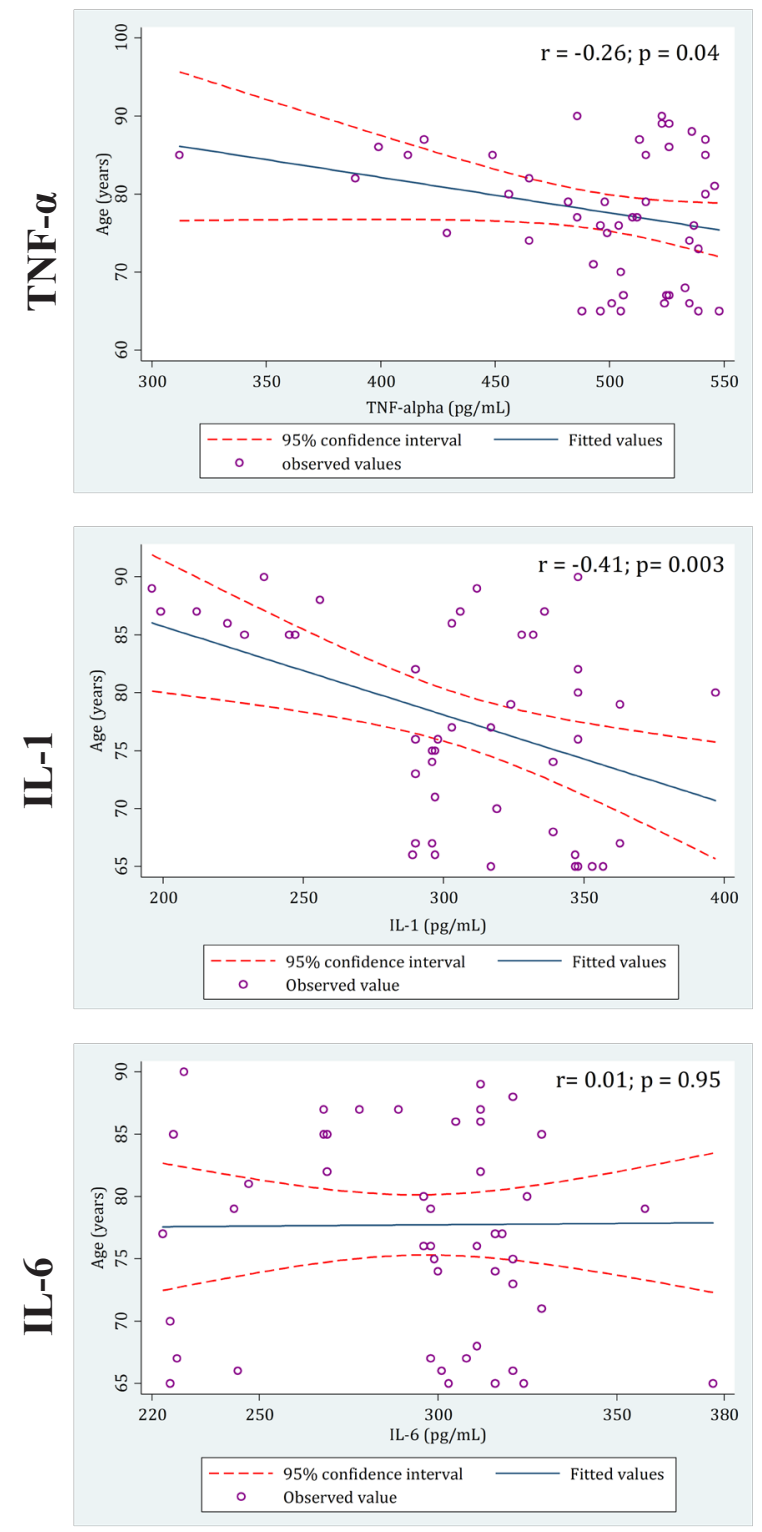

\section{Case}
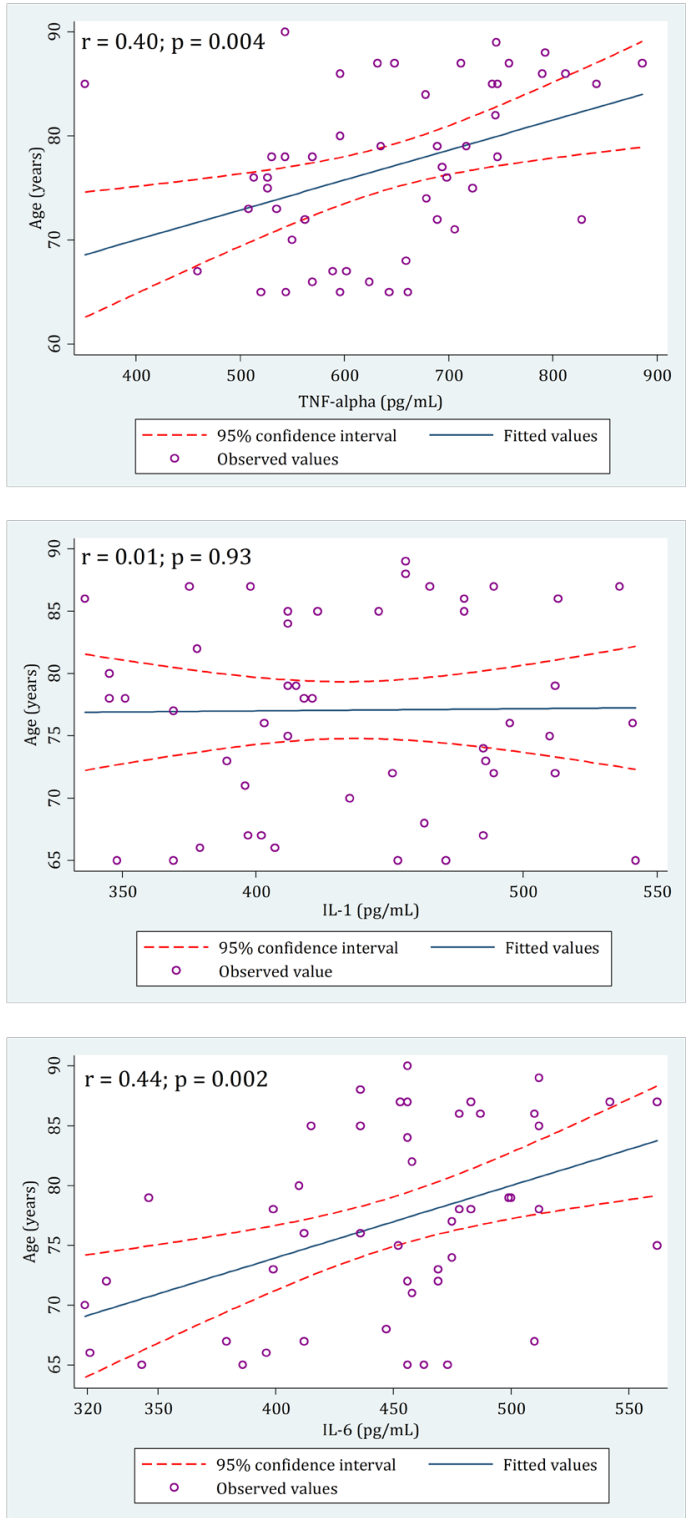

IL-1: interleukin 1; IL-6: interleukin 6; TNF- $\alpha$ : tumor necrosis factor alpha

Fig.1: The correlation between assessed cytokines and the participants' age in the case and the control groups

and TNF- $\alpha$ level $(\mathrm{r}=-0.26 ; p=0.04)$ as well as IL-1 level $(\mathrm{r}=-0.41 ; p=0.003)$, while no significant correlation between IL-6 level and age was observed $(\mathrm{r}=0.01$; $p=0.95)$. However, in the case group, the correlations between age and TNF- $\alpha(\mathrm{r}=0.40 ; p=0.004)$ and IL-6 $(\mathrm{r}=0.44 ; p=0.002)$ levels were direct, while no correlation was detected between IL-1 level and age $(\mathrm{r}=0.01 ; p=0.93)$.

\section{DISCUSSION}

Intestinal microbiota has a key role in modulation of immunit. ${ }^{19-21}$ Any pathological conditions such as constipation may alter this immunity, leading to hyper-secretion of some inflammatory biomarkers such as cytokines and chemokine. ${ }^{22}$ Moreover, intestinal microbiota plays a role in protection of a constant gut mucosa and in production of short chain fatty acids in a favorable ratio. ${ }^{23}$ Several 
studies have shown a reduction in Bifidobacteria and elevations in Lactobacilli, Streptococci, Enterobacteriaceae, and Clostridia in the intestinal microflora of elderly people, especially those who suffer from constipation., ${ }^{9,24}$ These alterations in the gut microflora can change the metabolic environment of the colon with important alterations in the concentration of physiologically active substances, which may modify the gut motor and secretory function. ${ }^{22}$ Consequently, Bifidobacteria, and more importantly lactic acid bacteria, are key components of a good, and balanced gut microbiota and are regularly applied as probiotics. ${ }^{14}$ Further microflora alterations enhance susceptibility to gastrointestinal functional disorders, inflammation, infections, or even cancers. ${ }^{16}$

Some studies demonstrated that the gut microbiota in elderly differs from that in younger adults. Pathogenic Enterobacteria and putrefactive Clostridia increased, and also Bifidobacterial and Lactobacilli decreased and the absence of bacteria was supposed to be advantageous for health. Also, similar analysis of the intestinal microbiota composition and the inflammatory markers demonstrated that pro-inflammatory cytokines elevation in the peripheral blood correlates with modifications in the intestinal microbiota profile. ${ }^{16}$

Aging can also decrease the TH1/TH2 ratio and enhance the generation of pro-inflammatory cytokines, including IL6, and TNF- $\alpha$. These modifications can result in a greater susceptibility to diseases such as constipation. It seems that the amplification of the number of Bifidobacteria can improve constipation, which is a strategy of using prebiotics as well as probiotic. ${ }^{25}$

Although the increasing number of old age individuals makes it interesting to work in this field, there are still limited studies focussing on the intestinal microbiota modifications and their probable consequences on elderly health status. It has been claimed that age-related atypically motivated immune response to the factors of intestinal microbiota triggers inflammatory process. ${ }^{16}$

Regulation of the inflammatory response to bacteria is affected by Toll-like receptors (TLRs). The expression level of TLRs on the intestinal epithelium is sophisticated to avoid over- and lasting stimulation. The gastrointestinal microbiota can change this response. The mentioned mechanism can explain the close relation between alteration in cytokines secretion mediated by microbiota and inflammatory-based response in constipation. ${ }^{26}$ Regarding the increased level of cytokines, in inflammatory conditions, macrophages produce various cytokines and growth factors as inflammatory reactions. These macrophages can be activated by pro-inflammatory mediators like TNF- $\alpha$, IL-1, IL-6. ${ }^{27,28}$

Our study showed higher levels of IL-1, IL-6, and TNF- $\alpha$ in old age patients with chronic constipation, compared with the population without this complaint. Also, the age-related differences in the intestinal microbiota and constipation was found by measuring the levels of TNF- $\alpha$, IL-1, and IL-6 in plasma samples of the two groups (participants with and without constipation). The increase in the serum inflammatory cytokines may correlate with changes in the intestinal microbiota profile and consequently constipation. The inflammatory response to this pathological condition can be mediated by alteration in intestinal microbiota condition. ${ }^{29}$

Reviewing the literature showed no similar studies to our survey with respect to the role of microbiota and stimulation of its secretory functions in relation to constipation. However, several studies investigated this pathway in those with irritable bowel syndrome. Gwee and colleages ${ }^{30}$ primarily performed a research that led to the discovery of the enhanced levels of IL-1 $\beta$ mRNA expression in patients with irritable bowel syndrome after a gastrointestinal infection. Moreover, O’Mahony and co-workers ${ }^{30}$ found an atypical ratio of immunoregulatory/proinflammatory IL-10/IL-12 cytokines in such patients. In recent observations, Liebregts and others ${ }^{31}$ indicated a considerable increase in the levels of released pro-inflammatory cytokines including TNF- $\alpha$, IL-1, and IL-6 from mononuclear cells in patients with inflammatory conditions. O'Mahony and colleagues ${ }^{32}$ recently revealed a higher TNF- $\alpha$ production in the animal models of irritable bowel syndrome. Elena Biagi ${ }^{16}$ confirmed the fact that aging procedure profoundly affected the construction of the human intestinal microbiota and its homeostasis with the host's immune system. In their extremely old and therefore susceptible microbiota model, a reorganization was reported in Butyrate creators and other 
anti-inflammatory bacteria, including Faecalibacterium prausnitzii. The resulting dysbiosis may be among the causes or the outcomes of opportunistic Enterobacteria proliferation, which seemed to positively correlate with enhancement in some pro-inflammatory signals (IL6 and IL8). Macfarlane ${ }^{33}$ reported that short term symbiotic application could efficiently ameliorate the composition and metabolic functions of colonic bacterial communities and immune factors in old age people. Finally, Clarke and co-workers ${ }^{34}$ showed a significant correlation between IL-6 and immune activation pathways. ${ }^{34}$ It seems that the inflammatory pathways in constipation may be very similar to those explained in irritable bowel syndrome. However, these mechanisms should be assessed further, particularly regarding the level of gene expression and molecular medicine.

\section{CONCLUSION}

The present study demonstrared a significant association between the serum levels of inflammatory modulating cytokines and age-related constipation in Iranian subjects. It seems that the serum level of modulating inflammatory cytokines can be affected by the diversity and abundance in the gut microbiota. The role of diversity in microbial population and their abundance in gut must be evaluated in further studies.

\section{CONFLICT OF INTEREST}

The authors declare no conflict of interest related to this work.

\section{REFERENCES}

1. O'Toole PW, Jeffery IB. Gut microbiota and aging. Science 2015;350:1214-5. doi: 10.1126/science.aac8469.

2. Dethlefsen L, Huse S, Sogin ML, Relman DA. The pervasive effects of an antibiotic on the human gut microbiota, as revealed by deep $16 \mathrm{~S}$ rRNA sequencing. PLoS Biol 2008;6:e280. doi: 10.1371/journal.pbio.0060280.

3. Mäkivuokko H, Tiihonen K, Tynkkynen S, Paulin L, Rautonen N. The effect of age and non-steroidal antiinflammatory drugs on human intestinal microbiota composition. Br J Nutr 2010;103:227-34. doi: 10.1017/ S0007114509991553.

4. Bartosch S, Fite A, Macfarlane GT, McMurdo ME. Characterization of bacterial communities in feces from healthy elderly volunteers and hospitalized elderly patients by using real-time PCR and effects of antibiotic treatment on the fecal microbiota. Appl Environ Microbiol 2004;70:3575-81. doi: 10.1128/AEM.70.6.35753581.2004

5. Hopkins MJ, Sharp R, Macfarlane GT. Age and disease related changes in intestinal bacterial populations assessed by cell culture, 16S rRNA abundance, and community cellular fatty acid profiles. Gut 2001;48:198-205. doi: 10.1136/gut.48.2.198.

6. Stephen AM, Wiggins HS, Cummings JH. Effect of changing transit time on colonic microbial metabolism in man. Gut 1987;28:601-9. doi: 10.1136/gut.28.5.601

7. International phd programme in neuropharmacology university of Catania JULY 12,2013.

8. Zoppi G, Cinquetti M, Luciano A, Benini A, Muner A, Bertazzoni Minelli E. The intestinal ecosystem in chronic functional constipation. Acta Paediatr 1998;87:836-41. doi: 10.1111/j.1651-2227.1998.tb01547.x.

9. Kang DW, DiBaise JK, Ilhan ZE, Crowell MD, Rideout JR, Caporaso JG, Rittmann BE, Krajmalnik-Brown R. Gut microbial and short-chain fatty acid profiles in adults with chronic constipation before and after treatment with lubiprostone. Anaerobe 2015;33:33-41. doi: 10.1016/j. anaerobe.2015.01.005

10. Pontes FA, Silva AT, Cruz AC. Colonic transit times and the effect of lactulose or lactitol in hospitalized patients. Eur J Gastroenterol Hepatol 1995;7:441-6.

11. Bazzocchi G, Ellis J, Villanueva-Meyer J, Jing J, Reddy SN, Mena I, et al. Postprandial colonic transit and motor activity in chronic constipation. Gastroenterology 1990;98:686-93. doi: 10.1016/0016-5085(90)90289-

12. Ross DG. Subjective data related to altered bowel elimination patterns among hospitalized elder and middleaged persons. Orthop Nurs 1993;12:25-32.

13. Lathrop SK, Bloom SM, Rao SM, Nutsch K, Lio CW, Santacruz N, et al. Peripheral education of the immune system by colonic commensal microbiota. Nature 2011;478:250-4. doi: 10.1038/nature10434.

14. Reikvam DH, Erofeev A, Sandvik A, Grcic V, Jahnsen FL, Gaustad P, et al. Depletion of murine intestinal microbiota: effects on gut mucosa and epithelial gene expression. PLoS One 2011;6:e17996. doi: 10.1371/journal. pone.0017996.

15. Gaboriau-Routhiau V, Rakotobe S, Lécuyer E, Mulder I, Lan A, Bridonneau $\mathrm{C}$, et al. The key role of segmented filamentous bacteria in the coordinated maturation of gut helper T cell responses. Immunity 2009;31:677-89. doi: 10.1016/j.immuni.2009.08.020.

16. Biagi E, Nylund L, Candela M, Ostan R, Bucci L, Pini E, et al. Through ageing, and beyond: gut microbiota and inflammatory status in seniors and centenarians. PLOS One 2010;5:e10667. doi: 10.1371/journal.pone.0010667.

17. Cockrell JR, Folstein MF. Mini-Mental State Examination (MMSE). Psychopharmacol Bull 1988;24:689-92. 
18. Kahle-Wrobleski K, Corrada MM, Li B, Kawas CH. Sensitivity and specificity of the mini-mental state examination for identifying dementia in the oldest-old: the $90+$ study. J Am Geriatr Soc 2007;55:284-9.

19. Lee YK, Mazmanian SK. Has the microbiota played a critical role in the evolution of the adaptive immune system? Science 2010;330:1768-73. doi: 10.1111/j.15325415.2007.01049.x

20. Fung TC, Olson CA, Hsiao EY. Interactions between the microbiota, immune and nervous systems in health and disease. Nat Neurosci 2017;20:145-55. doi: 10.1038/nn.4476.

21. Erdman SE, Poutahidis T. Gut microbiota modulate host immune cells in cancer development and growth. Free Radic Biol Med 2017;105:28-34. doi: 10.1016/j.freeradbiomed.2016.11.013.

22. Brown K, DeCoffe D, Molcan E, Gibson DL. Diet-induced dysbiosis of the intestinal microbiota and the effects on immunity and disease. Nutrients 2012;4:1095119. doi: $10.3390 /$ nu4081095.

23. Tojo R, Suárez A, Clemente MG, de los Reyes-Gavilán CG, Margolles A, Gueimonde M, et al. Intestinal microbiota in health and disease: role of bifidobacteria in gut homeostasis. World J Gastroenterol 2014;20:15163-76. doi: 10.3748/wjg.v20.i41.15163

24. Saunier K, Doré J. Gastrointestinal tract and the elderly: functional foods, gut microflora and healthy ageing. Dig Liver Dis 2002;34 Suppl 2:S19-24.

25. Gwee KA, Collins SM, Read NW, Rajnakova A, Deng Y, Graham JC, et al. Increased rectal mucosal expression of interleukin 1 beta in recently acquired post-infectious irritable bowel syndrome. Gut 2003;52:523-6. doi: 10.1136/ gut.52.4.523

26. Testro AG, Visvanathan K. Toll-like receptors and their role in gastrointestinal disease. $J$ Gastroenterol Hepatol 2009;24:943-54. doi: 10.1111/j.1440-1746.2009.05854.x.

27. Anderson CF, Mosser DM. A novel phenotype for an activated macrophage: the type 2 activated macrophage. $J$ Leukoc Biol 2002;72:101-6.

28. Mosser DM. The many faces of macrophage activation. J Leukoc Biol 2003;73:209-12. doi: 10.1189/jlb.0602325

29. Cario E, Brown D, McKee M, Lynch-Devaney K, Gerken G, Podolsky DK. Commensal-associated molecular patterns induce selective toll-like receptor-trafficking from apical membrane to cytoplasmic compartments in polarized intestinal epithelium. Am J Pathol 2002;160:165-73. doi: 10.1016/S0002-9440(10)64360-X

30. O’Mahony L, McCarthy J, Kelly P, Hurley G, Luo F, Chen K, et al. Lactobacillus and bifidobacterium in irritable bowel syndrome: symptom responses and relationship to cytokine profiles. Gastroenterology 2005;128:541-51. doi: $10.1053 /$ j.gastro.2004.11.050

31. Liebregts T, Adam B, Bredack C, Röth A, Heinzel S, Lester $\mathrm{S}$, et al. Immune activation in patients with irritable bowel syndrome. Gastroenterology 2007;132:913-20.
32. Kim SE, Choi SC, Park KS, Park MI, Shin JE, Lee TH, et al; Constipation Research group of Korean Society of Neurogastroenterology and Motility. Change of Fecal Flora and Effectiveness of the Short-term VSL\#3 Probiotic Treatment in Patients With Functional Constipation. J Neurogastroenterol Motil 2015;21:111-20. doi: 10.5056/jnm14048.

33. Yeun Y, Lee J. Effect of a double-coated probiotic formulation on functional constipation in the elderly: a randomized, double blind, controlled study. Arch Pharm Res 2015;38:1345-50. doi: 10.1007/s12272-014-0522-2.

34. Scott KP, Martin JC, Duncan SH, Flint HJ. Prebiotic stimulation of human colonic butyrate-producing bacteria and bifidobacteria, in vitro. FEMS Microbiol Ecol 2014;87:30-40. doi: 10.1111/1574-6941.12186. 